\title{
Measurement of Prestressing Force in Pretensioned UHPC Deck Using a Fiber Optic FBG Sensor Embedded in a 7-Wire Strand
}

\author{
Jae-min Kim, ${ }^{1}$ Hyun-woo Kim, ${ }^{2}$ Song-yi Choi, ${ }^{3}$ and Sung-yong Park ${ }^{4}$ \\ ${ }^{1}$ Department of Marine and Civil Engineering, Chonnam National University, Yeosu, Jeonnam 59626, Republic of Korea \\ ${ }^{2}$ Long Span Bridge Management Center, Korea Infrastructure Safety \& Technology Corporation (KISTEC), \\ Yeosu, Jeonnam 59768, Republic of Korea \\ ${ }^{3}$ Department of Civil and Environmental Engineering, Graduate School, Chonnam National University, \\ Yeosu, Jeonnam 59626, Republic of Korea \\ ${ }^{4}$ Department of Structural Engineering Research, Korea Institute of Civil Engineering \& Building Technology (KICT), \\ Goyang, Gyeonggi 10223, Republic of Korea
}

Correspondence should be addressed to Jae-min Kim; jm4kim@jnu.ac.kr

Received 16 March 2016; Accepted 15 June 2016

Academic Editor: Marco Consales

Copyright (C) 2016 Jae-min Kim et al. This is an open access article distributed under the Creative Commons Attribution License, which permits unrestricted use, distribution, and reproduction in any medium, provided the original work is properly cited.

\begin{abstract}
This paper presents the results of the performance test and long-term monitoring of the prestressing force inside concrete performed on a pretensioned Ultra-High Performance Concrete (UHPC) deck. The force is measured by applying a 7-wire strand embedded with an FBG (Fiber Bragg Grating) sensor. The performance test was conducted on a $3.7 \mathrm{~m} \times 1.8 \mathrm{~m}$ pretensioned deck specimen through wheel loading tests to verify the applicability of the measurement method. In addition, a $12.3 \mathrm{~m}$ long and $4.8 \mathrm{~m}$ wide bridge with a pretensioned UHPC deck was erected and long-term monitoring was conducted over three years to verify the applicability of the method to real bridges. The effectiveness of the measurement method of the prestressing force inside concrete is verified, and the long-term monitoring data are used to investigate various temperature compensation methods. The results show that the proposed method enables effective measurement of small changes in the prestressing force inside the concrete. These changes are caused by the external forces acting on the bridge in service and provide sufficient durability for long-term sensing. The analysis of the prestressing force obtained through long-term monitoring reveals the necessity of conducting temperature compensation for the consistency of the data acquired using the FBG sensor. Moreover, the selection of the thermal expansion coefficient appears also to be of critical importance for temperature compensation.
\end{abstract}

\section{Introduction}

Prestressed concrete (PSC) structures are widely used because of their reduced cracking and enhanced elastic recovery when compared to conventional reinforced concrete. In particular, recent advances in the material technology for bridges boosted research regarding the erection of more efficient and economical bridges and resulted in wider applications of PSC structures [1-3]. Besides, active research was conducted on various sensors and monitoring techniques following the increasing importance associated with Structural Health Monitoring (SHM) in the field of maintenance [4-7].

Among the sensors used in SHM, the FBG (Fiber Bragg Grating) sensor utilizes the change in the refractive index of light. This is in contrast to the conventional electromechanical sensor, which uses electric signals. Extensive studies are being conducted on the utilization of the optical fiber sensor because it is immune to electromagnetic interference, is of small size, exhibits outstanding sensitivity, and can perform measurements at remote locations dozens of kilometers away. The FBG sensor is applied in various domains since it can measure various quantities and a single line can measure several locations [8-17].

A review of previous works related to the measurement of prestressing force in structures using the FBG sensor, similar to the present study, reveals that this research was conducted using methods of mounting the sensor on the outer surface of the prestressed member, inserting the sensor within the 


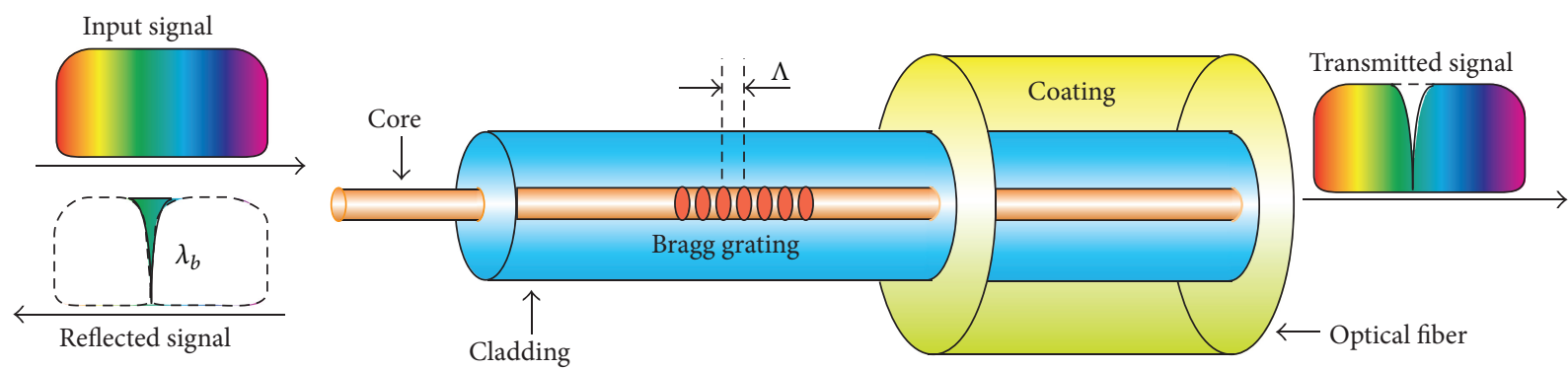

(a)

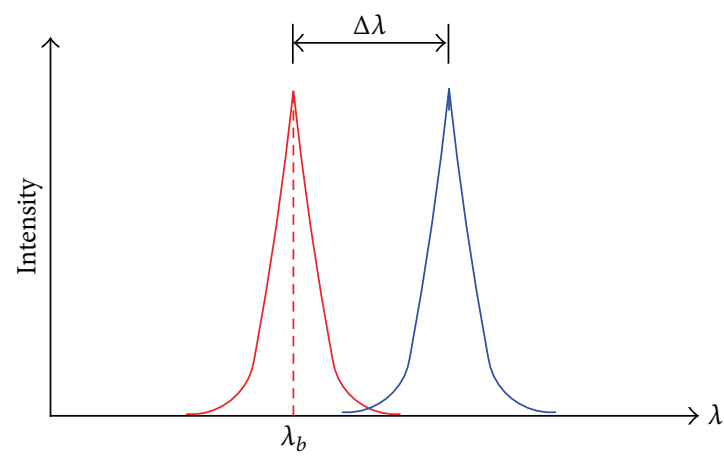

(b)

FIGURE 1: Fundamentals of FBG sensor: (a) principle of FBG sensor; (b) wavelength shift due to temperature and/or elastic strain change.

load cell at the jacking end, or combining the sensor with the strand using an advanced material with similar properties [10-13]. However, these methods fail to provide accurate measurement of the prestressing force inside the concrete because the sensor is attached on the outer surface of the PSC member. Moreover, the material heterogeneity between the sensor and the prestressed member is likely to provoke various problems in terms of field-applicability and constructability. In order to solve these problems, Kim et al. [7, 14-16] presented and studied a method of measuring the prestressing force inside the concrete by encapsulating the sensor in the 7-wire strand that is widely used in prestressed members. Thus, it is able to simultaneously fulfill the roles of sensor and reinforcement.

This study applies the 7-wire strand with encapsulated FBG sensor and monitors the change in the prestressing force inside the concrete of a pretensioned Ultra-High Performance Concrete (UHPC) deck. To that goal, a wheel loading test is first performed on the pretensioned deck to verify the applicability and durability of the sensor-embedded tendon. The sensor is then applied to the pretensioned deck of an actual bridge to conduct a field load test, followed by longterm monitoring over three years. In addition, a computation method for the temperature compensation coefficient is derived for the 7-wire strand embedded with the FBG sensor using the measurements and the atmospheric temperature data. The results show that the steel strand adopted in this study is seen to enable effective measurement of the change in the internal prestressing force. In addition, the efficiency of the long-term monitoring of the change in the prestressing force and temperature compensation method are verified.

\section{Seven-Wire Strand with Embedded FBG Sensor}

2.1. FBG Sensor. The FBG (Fiber Bragg Grating) sensor modifies the reflective index of the optical fiber by grating it with periodic lattices using UV laser irradiation as depicted in Figure 1(a). As shown in Figure 1(b), the FBG sensor measures the temperature and the strain by measuring the change in the reflected wavelength reacting to the change in the external physical quantity. In terms of its properties, the FBG sensor offers high sensitivity, secures the linearity of the measured values, is immune to electromagnetic interference (EMI), is resistant to high temperatures, and enables multiplexing with only one line. However, the sensor is manufactured from glass, which makes it fragile and prone to damage on site and stresses the crucial importance to protect it.

As shown in Figure 1(a), when the light wavelength spectrum is launched in the FBG sensor, the wavelength corresponding to the conditions of the Bragg gratings is reflected while the other wavelengths pass through. The center wavelength $\left(\lambda_{B}\right)$ of the reflected light varies with respect to the refractive index of the optical fiber $\left(n_{\text {eff }}\right)$ and the spacing $(\Lambda)$ between the gratings, as expressed in (1). The gratings spacing varies due to the change in the external physical quantity and appears through the shift of the reflected wavelength [17]:

$$
\lambda_{B}=2 n_{\mathrm{eff}} \Lambda
$$



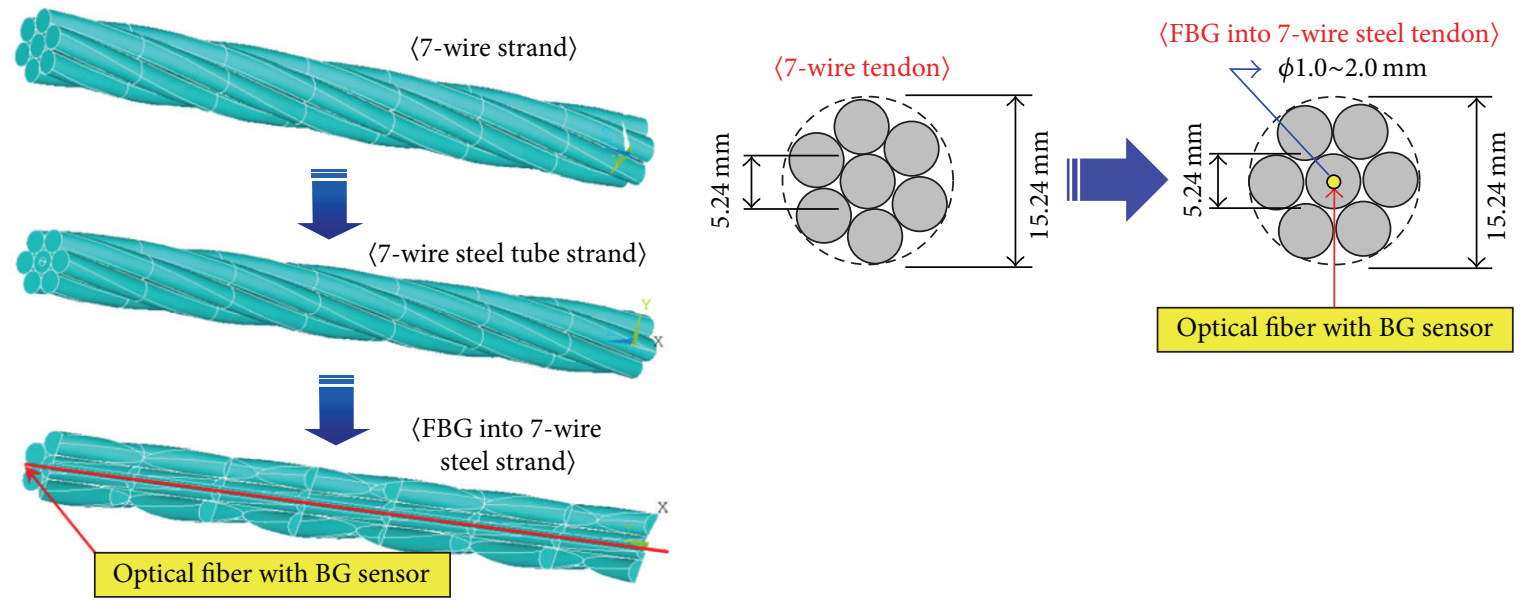

FIGURE 2: Concept of in-strand FBG sensor.

Here, the shift of the reflected wavelength $(\Delta \lambda)$ is expressed in (2) as a function of the stress-induced strain $(\Delta \varepsilon)$ and the temperature gradient $(\Delta T)$ :

$$
\frac{\Delta \lambda}{\lambda_{B}}=\left(1-p_{e}\right) \Delta \varepsilon+(\alpha+\xi) \Delta T,
$$

where $p_{e}$ is the effective strain-optic constant $(0.22$ for silica), $\alpha$ the thermal expansion coefficient of the optical fiber $\left(0.550 \times 10^{-6} /{ }^{\circ} \mathrm{C}\right.$ for silica $), \Delta \varepsilon$ the effective strain, $\Delta T$ the temperature gradient, and $\xi$ the thermooptic coefficient $\left(8.60 \times 10^{-6} /{ }^{\circ} \mathrm{C}\right.$ for germanium-doped silica-core fiber $)$ [17]

Accordingly, the shift of the wavelength of the gratings caused by the application of the external physical quantity is measured by the factored sum of the strain and temperature.

2.2. Seven-Wire Strand with Embedded FBG Sensor. The 7wire strand adopted in PSC bridges typically has a diameter of $12.7 \mathrm{~mm}$ ( $0.5 \mathrm{in}$.) or $15.2 \mathrm{~mm}$ (0.6 in.) and is fabricated by combining a straight central wire, called a core or king wire, with six wires helically laid around the king wire. Figure 2 depicts the FBG sensor-embedded 7-wire strand used in this study. The FBG sensor is inserted inside a steel tube and fixed using epoxy resin with a low viscosity. This assemblage is then used to replace the king wire. Here, the diameter of the optical fiber is usually $0.25 \mathrm{~mm}$ and the inner diameter of the steel tube ranges from 1 to $2 \mathrm{~mm}$. The FBG sensor used in this study is fabricated by the phase-mask technique, and a proactive acrylate coating is applied over the grating. A peak reflectivity of $90 \%$ was observed for the grating approximately $10 \mathrm{~mm}$ long. The steel tube is made by the pultrusion process in which a welded steel pipe is pulled to fit the outer diameter of the tube. It is worth mentioning that the in-strand FBG sensor gives excellent performance in measuring the prestressing force [17].

\section{Wheel Loading Test of Pretensioned UHPC Deck}

3.1. Pretensioned UHPC Deck Specimen. In order to evaluate the durability and long-term performance of a tendon
TABLE 1: Material properties of UHPC.

\begin{tabular}{lc}
\hline Material properties & Value \\
\hline Compressive strength & $180 \mathrm{MPa}$ \\
Modulus of elasticity & $45,000 \mathrm{MPa}$ \\
Thermal expansion coefficient $\left(\alpha_{\mathrm{UHPC}}\right)$ & $1.20 \times 10^{-5}$ \\
Poisson's ratio & 0.20 \\
Unit weight & $25.5 \mathrm{kN} / \mathrm{m}^{3}$ \\
\hline
\end{tabular}

embedded with an FBG sensor, a full-scale pretensioned UHPC deck specimen was fabricated with length of $4.3 \mathrm{~m}$, width of $1.8 \mathrm{~m}$, and height of $0.26 \mathrm{~m}$, and the specimen was subjected to a wheel loading test as shown in Figure 3. The deck was fabricated by precasting UHPC, the properties of which are listed in Table 1 . Nine $\phi 15.2 \mathrm{~mm} 7$-wire tendons were applied for prestressing.

The FBG sensor-embedded strands were installed at the center of the deck, as shown in Figure 3, and jacked up to the target prestressing force of $176 \mathrm{kN}$ using a single hydraulic jack. Figure 4 shows the plot of the prestressing results estimated using strains reading from the FBG sensor. The final prestressing force reached $160.4 \mathrm{kN}$, which indicates the occurrence of an instantaneous loss of $12.3 \%$ of the maximum prestressing force due to the elastic shortening and slip on interface of the strand with the concrete at the ends of the strand. An additional loss of $8.8 \mathrm{kN}$ occurred in the prestressing force after the cutting of the ends for pretensioning, which resulted in a final prestress force of $151.6 \mathrm{kN}$.

3.2. Wheel Load Test. The wheel load test realistically simulates the crossing of a bridge by a vehicle by making the wheels pass repeatedly over the deck in the same location. This test can be conducted statically and dynamically to evaluate the fatigue durability of the deck. In this study, the wheel load test is not performed to evaluate the performance of the deck but to validate the performance and durability of the FBG sensor-embedded tendon. Therefore, the test was planned for this purpose. 


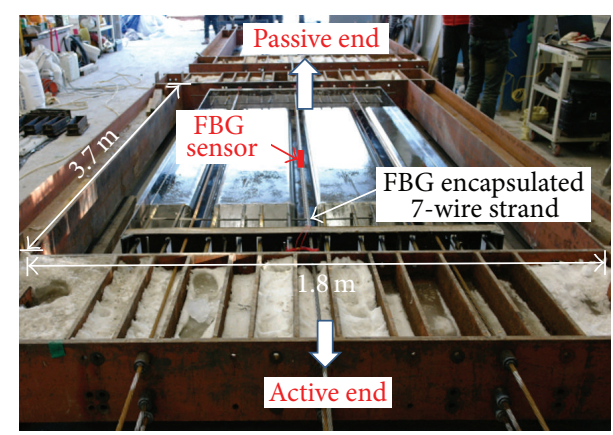

(a)

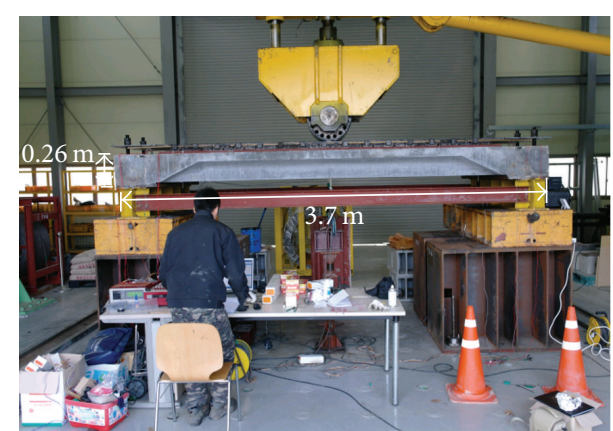

(b)

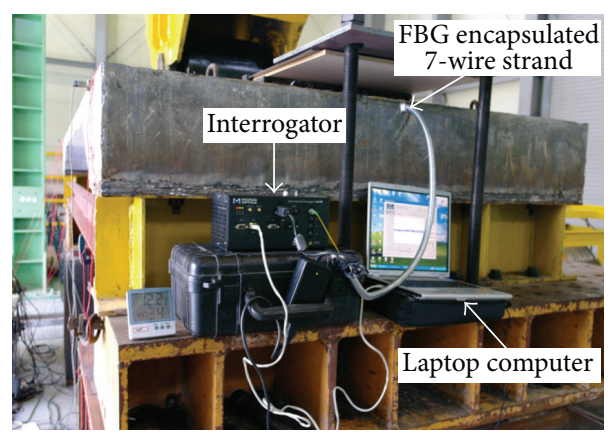

(c)

FIGURE 3: Wheel load test for UHPC deck: (a) fabrication of an UHPC deck; (b) wheel load testing; (c) monitoring system.

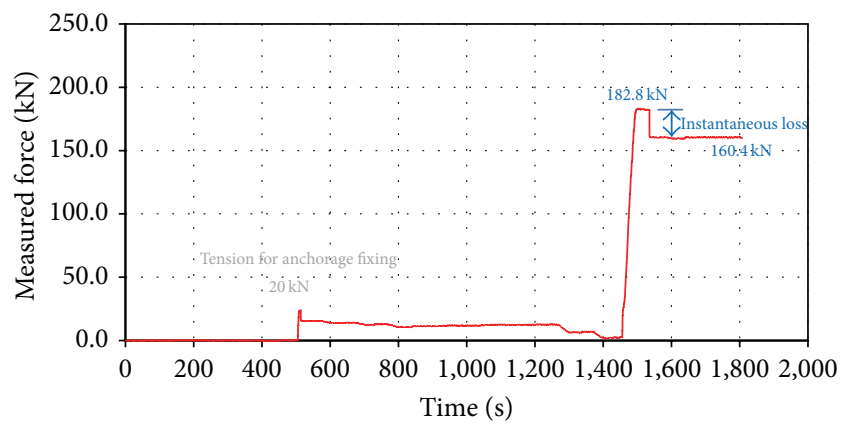

FIGURE 4: Monitored prestressing force during initial jacking for UHPC deck.

In the static test, a load of $124.8 \mathrm{kN}$, corresponding to the fatigue load of the deck, was applied at the center at a speed of $10 \mathrm{kN} / \mathrm{m}$ and a duration of ten minutes to evaluate the change in the prestressing force in the elastic region, as a function of a change in the load. In the dynamic test, two million loading cycles should be applied based on the service life of the bridge; however the test was executed for up to 50,000 cycles in view of the purpose of the test. Here, the same load of $124.8 \mathrm{kN}$ was applied at a frequency of $0.33 \mathrm{~Hz}$.

Figure 5 plots the results of the dynamic test for up to 20,000 cycles (left) and the static test (right). The change in the prestressing force appeared through the occurrence of a compressive force reaching a mean of $2.63 \mathrm{kN}$ in the dynamic test and ranging from $3.35 \mathrm{kN}$ to $3.48 \mathrm{kN}$ in the static test.
Moreover, the internal prestressing force caused by 50,000 wheel load cycles remained unchanged with a constant value of $150 \mathrm{kN}$, as shown in Figure 6. This indicates that the measurement method proposed in this study can efficiently monitor the stress change in a tendon subjected to an external load and that the in-strand FBG sensor can properly fulfill its role as a sensor in a long-term.

\section{Long-Term Monitoring of Prestressing Force in Pretensioned UHPC Deck}

4.1. Pretensioned UHPC Deck Installed on an Actual Bridge. The pretensioned UHPC deck adopted in this study is installed on a single span bridge with length of $12.3 \mathrm{~m}$ and width of $4.8 \mathrm{~m}$, as shown in Figures 7 and 8 . The superstructure is composed of three deck segments installed on two U-shape steel girders. Each segment was precast, installed on site, and connected by placing the UHPC. The material properties of the UHPC are identical to those of the deck specimen in Section 3.

The pretensioning of each deck segment was processed as follows: (1) installation of 24 tendons comprised of $\phi 15.2 \mathrm{~mm}$ 7-wire strands; (2) pretensioning up to approximately $200 \mathrm{kN}$ using a single hydraulic jack; (3) placing of UHPC and high temperature curing; and (4) cutting of strands. The 7-wire strand tendon embedded with the FBG sensor was installed at the top of the third segment on the right-hand side, as shown in Figure 7, and the change in the prestressing force was measured at the center of the segment. 

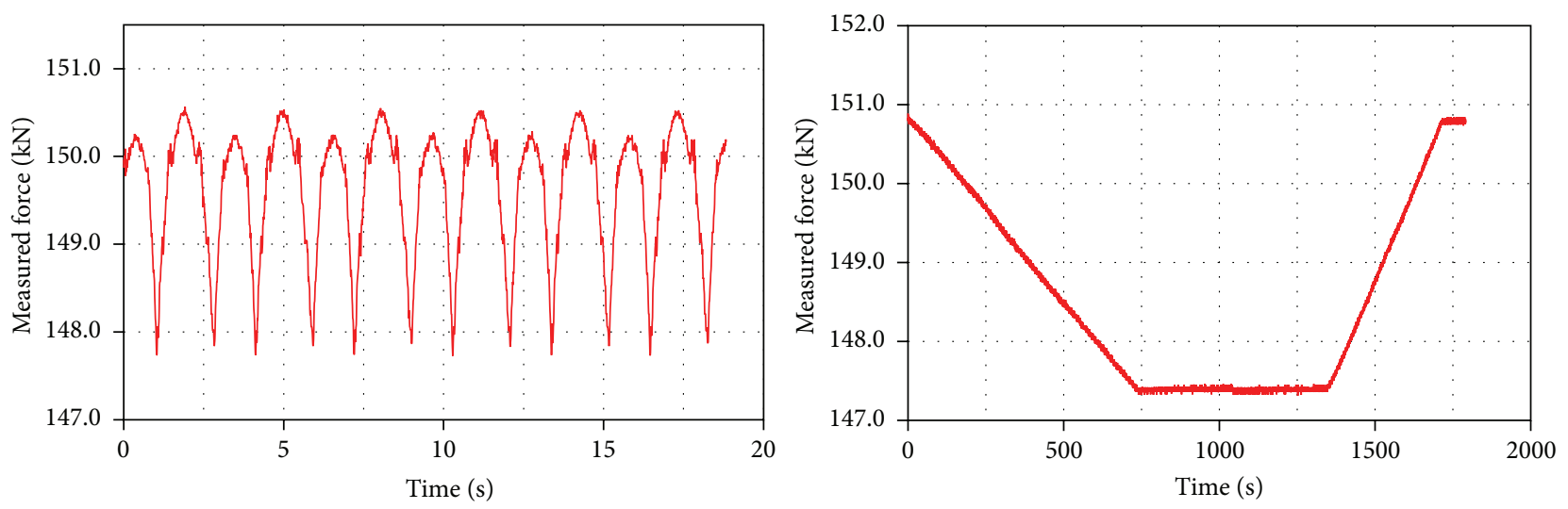

FIGURE 5: Monitoring results of dynamic and static wheel load tests (20,000 cycles).

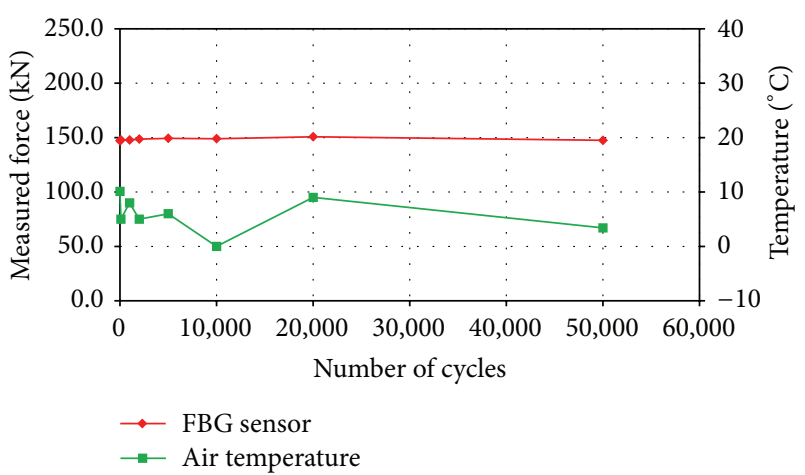

Figure 6: Monitoring results of dynamic wheel load test after 50,000 cycles.

4.2. Layout of FBG Sensor and Measurement of Prestressing Force. As shown in Figure 9, the FBG sensor-embedded strand was fabricated with a length of $8.0 \mathrm{~m}$. The FBG sensor was installed to allow the measurement of the prestressing force at the center of the third segment. The FBG sensorembedded strand was prestressed after pretensioning of all of the remaining strands.

An initial prestressing force of approximately $20 \mathrm{kN}$ was first introduced to fix the ends. Then, pretensioning was executed up to the design prestressing force of $211 \mathrm{kN}$. Figure 10 shows the plot of the prestressing force measured during the initial jacking of the FBG sensor-embedded strand. A maximum prestressing force of $239.5 \mathrm{kN}$ was measured before the occurrence of instantaneous loss. The final prestressing force was found to be $166.8 \mathrm{kN}$, which corresponds to a loss of $30.4 \%$ of the maximum prestressing force, due to instantaneous losses such as anchorage slip. In addition, the change in the prestressing force was measured after completion of the precasting of the UHPC segments and the cutting of the strands for the pretensioning. The results show a reduction of $9.1 \%$ in the final prestressing force with a value of $151.8 \mathrm{kN}$.

4.3. Field Load Test. Figure 11 shows photographs of the field load test using a $249.9 \mathrm{kN}$ truck (front wheel $=74.6 \mathrm{kN}$, rear wheel $=175.3 \mathrm{kN}$ ). Static loading test was adopted because of the difficulty in securing a sufficient acceleration section on the bridge. The truck was configured as shown in Figure 12 to position the front and rear wheels at the mid-span of the bridge. Figure 13 shows the plot of the prestressing force monitored by the FBG sensor for the considered load cases (LC) prior to temperature compensation.

In view of Figure 13, LC 1 and LC 2 provoked a slight reduction in the prestressing force by 0.18 and $0.12 \mathrm{kN}$, respectively, and LC 3 showed a reduction in the prestressing force of $0.93 \mathrm{kN}$. Such a reduction in the prestressing force can be explained by the occurrence of compressive stress in the concrete since the FBG sensor-embedded strand was installed above the centroid of the girder section, as shown in Figure 7.

4.4. Results of Long-Term Monitoring and Temperature Compensation. In order to manage the long-term prestressing force of the pretensioned deck, the prestressing force was measured at each construction stage. In addition, this change, as well as the atmospheric temperature, was measured during the three years following completion using the long-term monitoring system shown in Figure 11. Figure 14 shows the long-term monitoring results.

For the long-term monitoring using the FBG sensor, temperature compensation must be conducted to measure the effective strain because of the thermal sensitivity of the FBG sensor. Kim et al. [16] conducted indoor thermal tests and long-term monitoring taking into consideration this sensitivity. These authors stressed the necessity to compensate for the thermooptic coefficient $(\xi)$ of (2) according to the applied FBG sensor. They further examined the importance of applying the thermal expansion coefficient of the main member integrating the FBG sensor. Accordingly, this study considers the thermal expansion coefficient $\left(\alpha_{\text {textbook }}=\right.$ $\left.0.550 \times 10^{-6} /{ }^{\circ} \mathrm{C}\right)$ and the thermooptic coefficient $\left(\xi_{\text {textbook }}=\right.$ $8.60 \times 10^{-6} /{ }^{\circ} \mathrm{C}$ ) of germanium-doped silica [17], as well as the thermooptic coefficient $\left(\xi_{\mathrm{FBG}}=5.67 \times 10^{-6} /{ }^{\circ} \mathrm{C}\right)$ identified for the FBG sensor employed in this study [16]. Moreover, taking into account that the thermal expansion behavior of the deck is governed by UHPC, the thermal expansion coefficient of UHPC $\left(\alpha_{\text {UHPC }}=1.20 \times 10^{-5} /{ }^{\circ} \mathrm{C}\right)$ must be applied. 

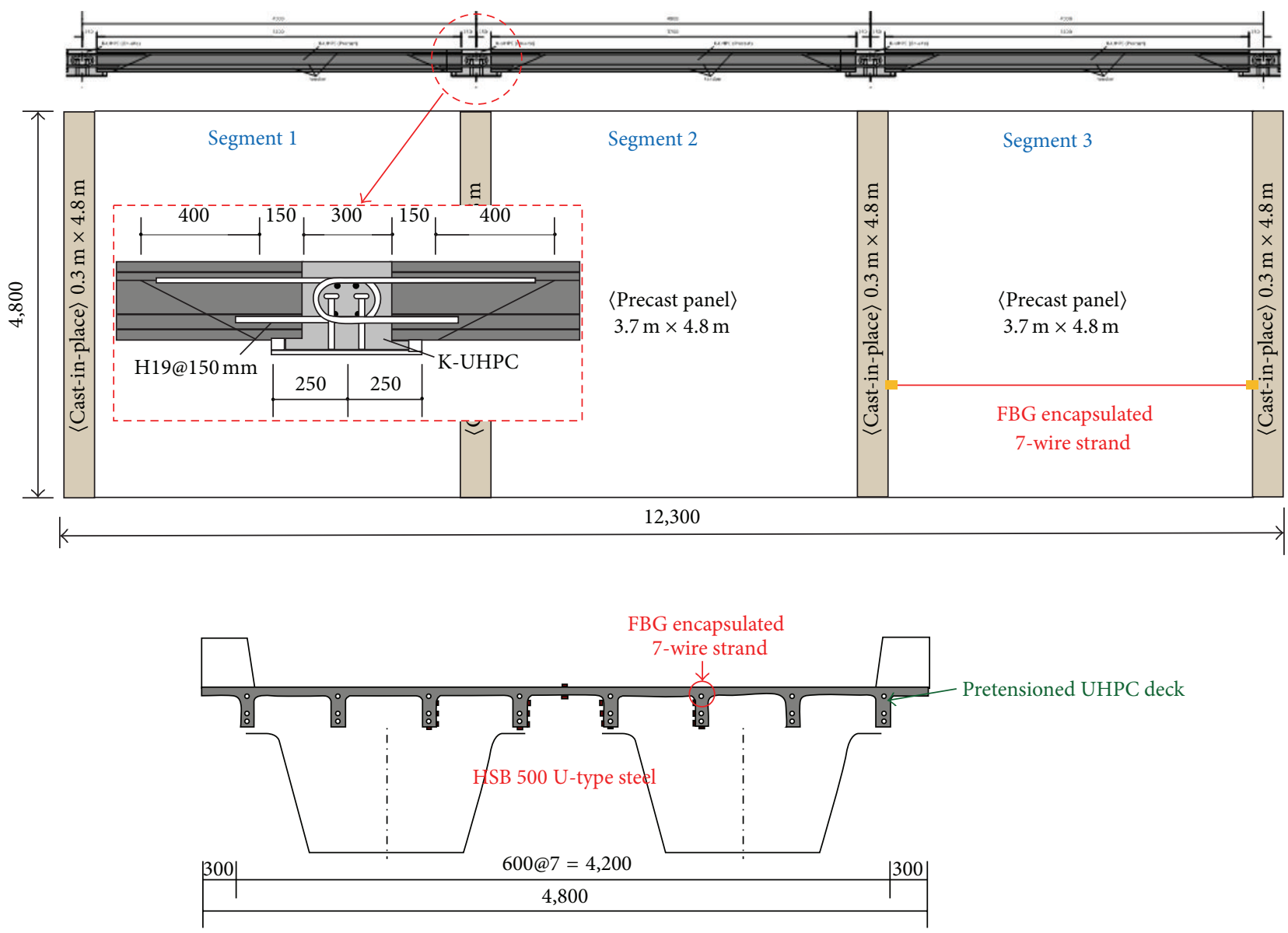

FIgURE 7: Dimensions of pretensioned UHPC deck.

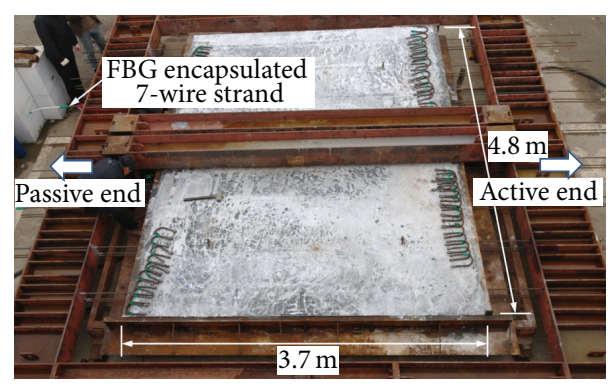

(a)

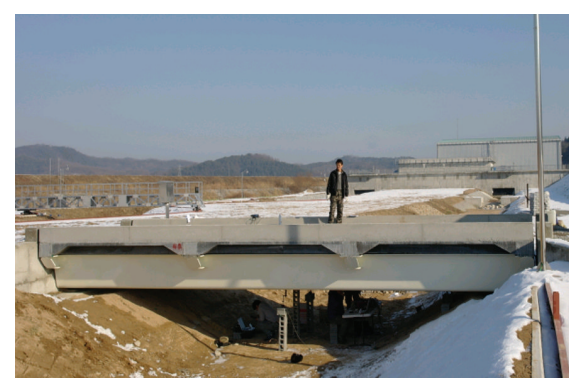

(b)

FIGURE 8: Installation of pretensioned UHPC deck: (a) manufactured segment; (b) completed installation.

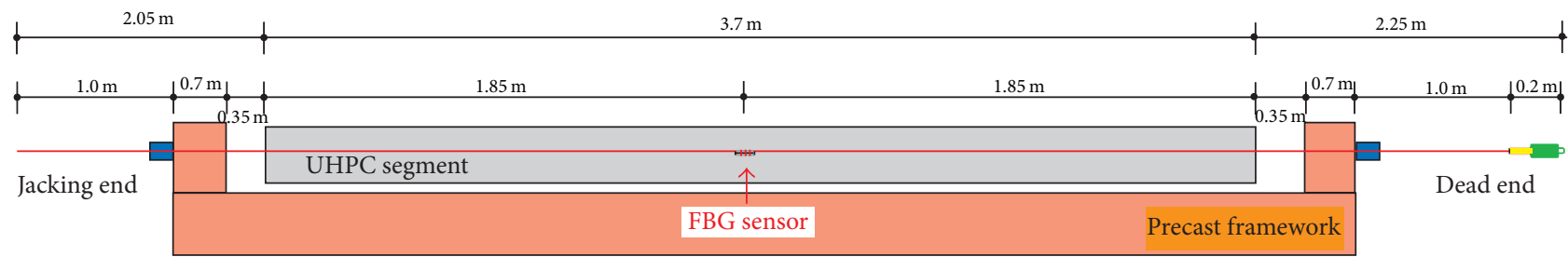

FIGURE 9: Location of the FBG sensor. 


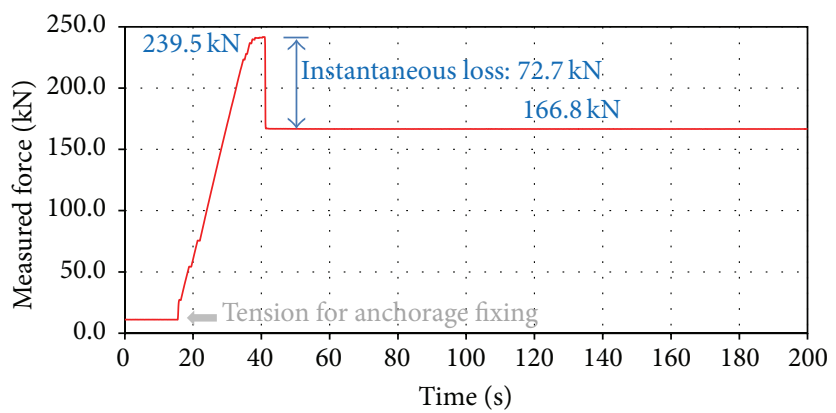

FIgURE 10: Monitored prestressing force during initial jacking (temperature $=12.0^{\circ} \mathrm{C}$ ).
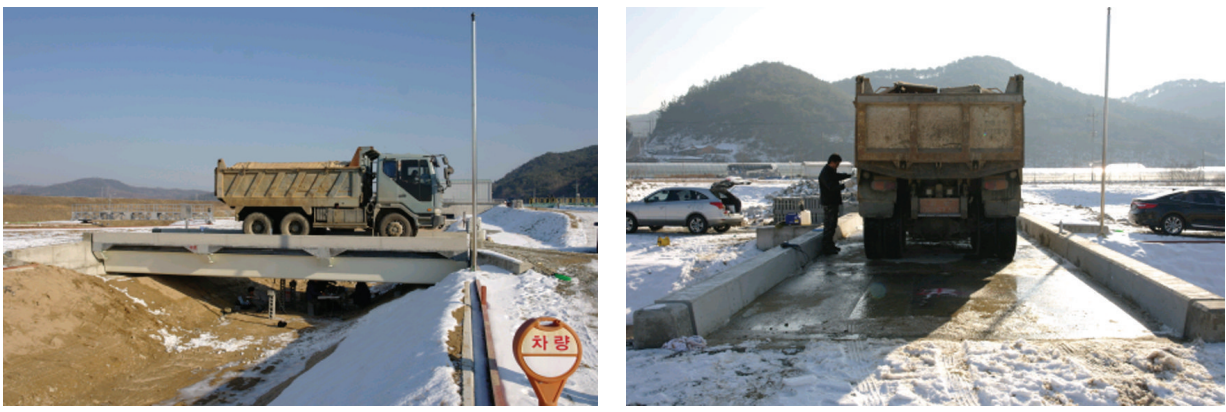

FIGURE 11: View of field load test.
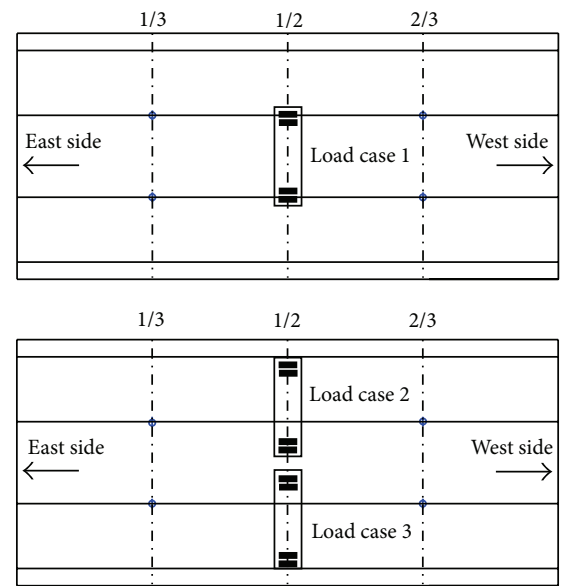

FIgURE 12: Overview of field load test.

The following four methods are investigated for temperature compensation in this study:

$$
\begin{aligned}
& \text { M1: } \Delta \varepsilon=\frac{1}{1-p_{e}} \frac{\Delta \lambda}{\lambda_{B}}, \\
& \text { M2: } \Delta \varepsilon=\frac{1}{1-p_{e}}\left(\frac{\Delta \lambda}{\lambda_{B}}-\left(\alpha_{\text {textbook }}+\xi_{\text {textbook }}\right) \Delta T\right), \\
& \text { M3: } \Delta \varepsilon=\frac{1}{1-p_{e}}\left(\frac{\Delta \lambda}{\lambda_{B}}-\left(\alpha_{\mathrm{UHPC}}+\xi_{\text {textbook }}\right) \Delta T\right), \\
& \text { M4: } \Delta \varepsilon=\frac{1}{1-p_{e}}\left(\frac{\Delta \lambda}{\lambda_{B}}-\left(\alpha_{\mathrm{UHPC}}+\xi_{\mathrm{FBG}}\right) \Delta T\right),
\end{aligned}
$$

where $\mathrm{M} 1$ is the prestressing force prior to temperature compensation and M2, M3, and M4 are the prestressing forces for which temperature compensation is executed using different thermal expansion coefficients and the thermooptic coefficient.

Temperature compensation was performed by these four methods and the corresponding changes in the prestressing force plotted in Figure 14 were analyzed. The results of the temperature compensation by the atmospheric temperature (T.C.BG1 in Figure 14) exhibit a difference larger than $11 \%$ compared to the prestressing force prior to temperature compensation (BG1 in Figure 14). Moreover, the temperature compensation by methods M3 and M4 results in consistent values of prestressing force, which indicates that these methods can be used in practice. The temperature compensation by M4 yields the smallest variation in measured values and provides a high reliability. However, the temperature compensation by $\mathrm{M} 2$ using the coefficients given in a textbook by Othonos and Kalli [17] shows a difference larger than 5\% compared to the results of M4, which seems to be a relatively large error that makes it improper for practical application.

Accordingly, when long-term monitoring of a structure is conducted using an FBG sensor, temperature compensation shall be executed to acquire consistent measurements independent of the external temperature. In addition, the application of the thermal expansion coefficient of the member on which the FBG sensor is mounted (UHPC in this study) appears to be of critical importance for the temperature compensation. 


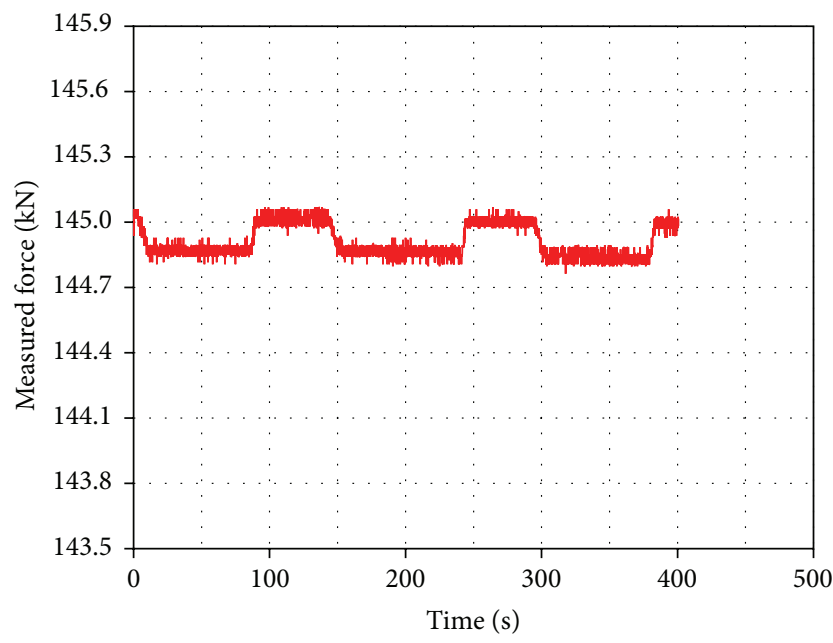

(a)

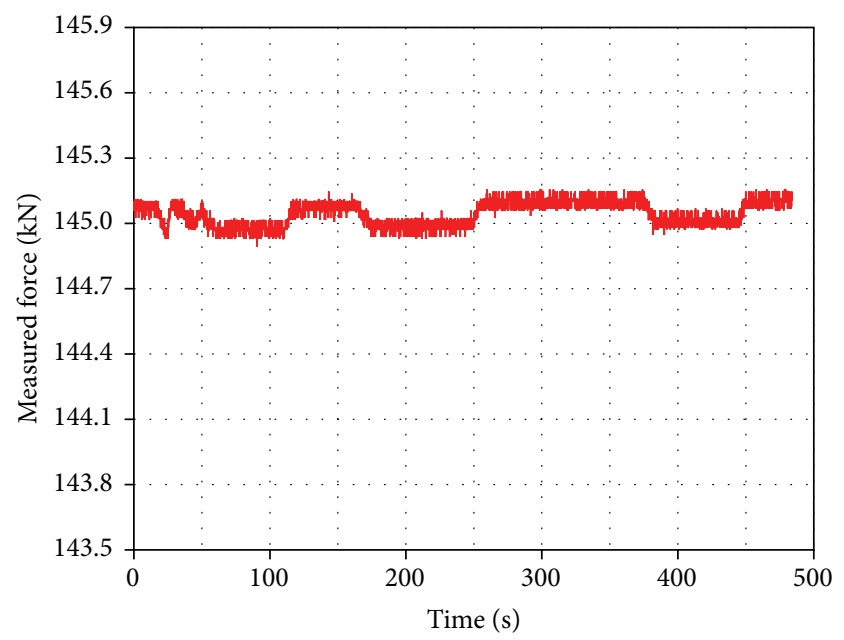

(b)

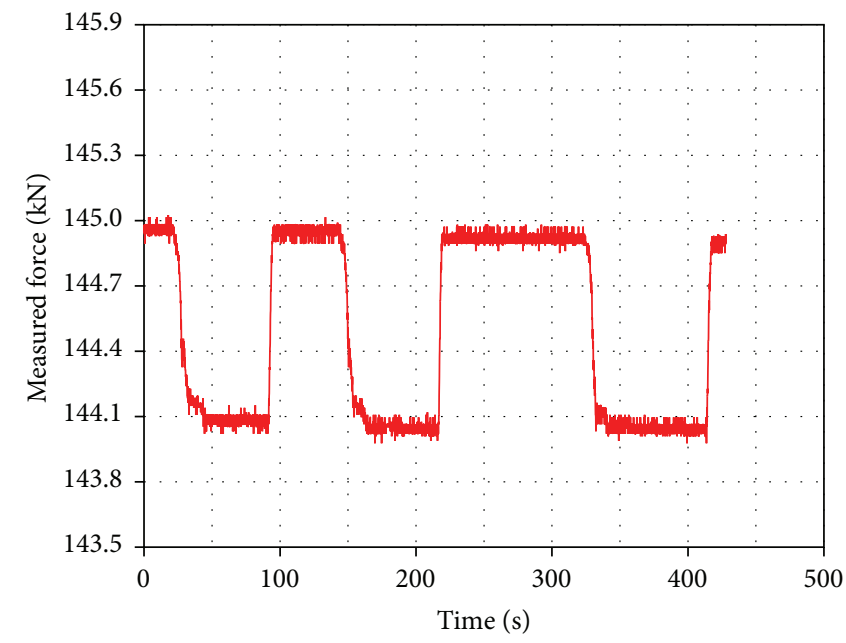

(c)

FIGURE 13: Monitoring results of field load test (temperature $=5.3^{\circ} \mathrm{C}$ ): (a) LC 1; (b) LC 2; (c) LC 3.

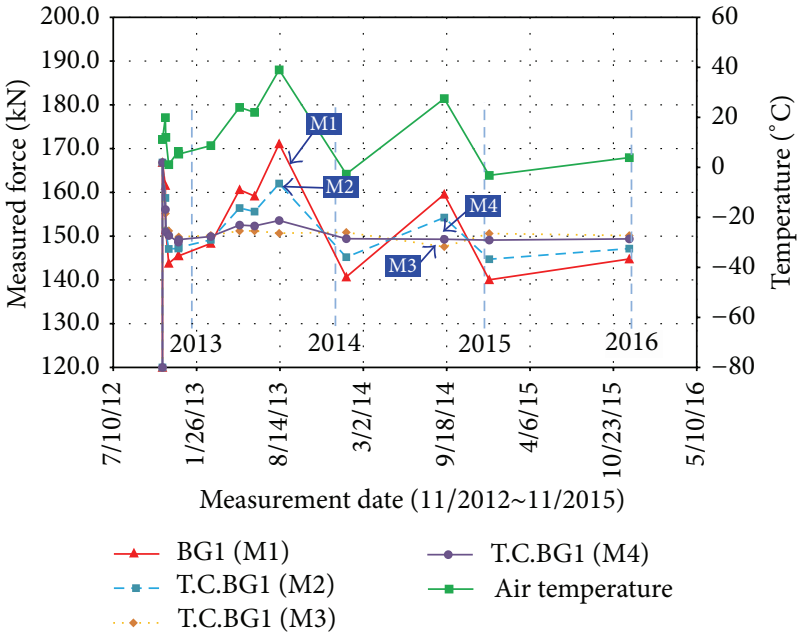

FIGURE 14: Long-term monitoring results over three years.

\section{Conclusions}

In this study, a series of performance tests and the long-term monitoring of the prestressing force inside concrete were conducted. This was achieved by applying a 7-wire strand embedded with an FBG sensor in a pretensioned UHPC deck specimen and a pretensioned UHPC deck installed on an actual bridge. The results verified the durability of the in-strand sensor method, measuring the prestressing force inside the concrete, proposed in this study, as well as the performance of the long-term monitoring during service. The results were then used to examine the methods of temperature compensation of the FBG sensor. The following conclusions can be drawn:

(1) The results of the wheel loading test of the deck verified that the proposed measurement method could efficiently measure the change in the stress inside 
concrete caused by external loads and that the instrand sensor could properly fulfill its sensing role in the long-term under cyclic loading.

(2) The field load tests performed on an actual bridge after its completion showed that it was possible to measure the change in the prestressing force inside concrete, even below $1.00 \mathrm{kN}$, and indicated the remarkable sensitivity of the in-strand sensor. The long-term monitoring conducted over three years demonstrated the applicability of the proposed method for measuring the prestressing force inside concrete.

(3) The prestressing force inside the concrete of the pretensioned deck installed on site was analyzed using the long-term monitoring results provided by the FBG sensor and the temperature data. The analysis revealed that the measurements without temperature compensation fluctuated by more than $11 \%$ compared to the final prestressing force and according to the variation in the atmospheric temperature. This observation stressed the necessity to perform temperature compensation on the results of the longterm monitoring using the FBG sensor to prevent misinterpretation of the reduction or increase in the prestressing force by the technician.

(4) The temperature compensation methods proposed in this study were compared. This comparison showed that methods M3 (applying $\alpha_{\mathrm{UHPC}}$ and $\xi_{\text {textbook }}$ ) and M4 (applying $\alpha_{\mathrm{UHPC}}$ and $\xi_{\mathrm{FBG}}$ ) were appropriate for practical application. In addition, the application of the thermal expansion coefficient of the member on which the FBG sensor is mounted appeared to be of critical importance for the temperature compensation. Finally, the effectiveness of the temperature compensation method proposed in this study was demonstrated.

\section{Competing Interests}

The authors declare that there are no competing interests regarding the publication of this paper.

\section{Acknowledgments}

This research was supported by a grant (14CTAP-C07842401) from Technology Advancement Research Program funded by the Ministry of Land, Infrastructure and Transport of the Korean government and a grant from a Strategic Research Project (Development of Smart Prestressing and Monitoring Technologies for Prestressed Concrete Bridges) funded by the Korea Institute of Civil Engineering \& Building Technology.

\section{References}

[1] S. Rizkalla and G. Tadros, FRP for Prestressing of Concrete Bridges in Canada, vol. 215 of ACI Special Publication, 2003.
[2] H. G. Russell and B. A. Graybeal, "Ultra-high performance concrete: a state of the art report for the bridge community," Federal Highway Administration FHWA-HRT-13-060, 2013.

[3] J. K. Kim, J. M. Yang, and H. J. Yim, "Transfer length in pretensioned prestressed concrete beam using high strength PS strand," in Proceedings of the World Congress on Advances in Structural Engineering and Mechanics (ASEM '15), Incheon, Republic of Korea, August 2015.

[4] M. L. Wang, "Long term health monitoring of post-tensioning box girder bridges," Smart Structures and Systems, vol. 4, no. 6, pp. 711-726, 2008.

[5] D. Inaudi, "Overview of 40 bridge structural health monitoring projects," in Proceedings of the International Bridge Conference (IBC '10), 2009.

[6] J. M. Kim, H. W. Kim, Y. H. Park, and Y. S. Kim, "Tension monitoring of a prestressing strand for concrete bridge using in-tendon FBG sensors," in Proceedings of the 5th International IABMAS Conference, pp. 205-210, Philadelphia, Pa, USA, July 2010.

[7] M. Kalicka and T. Vogel, "Long term monitoring of a prestressed concrete box girder bridge by acoustic emission-planning and executing," in Proceedings of the Structural Faults \& Repair, 14th International Conference \& Exhibition, Edinburgh, UK, July 2012.

[8] E. Udd, Fiber Optic Smart Structures, John Wiley \& Sons, New York, NY, USA, 1996.

[9] K.-T. Lau, "Fibre-optic sensors and smart composites for concrete applications," Magazine of Concrete Research, vol. 55, no. 1, pp. 19-34, 2003.

[10] S. Calvert and J. Mooney, "Bridge structural health monitoring system using fiber grating sensors: development and preparation for a permanent installation," in Smart Structures and Materials 2004: Sensors and Smart Structures Technologies for Civil, Mechanical, and Aerospace Systems, vol. 5391 of Proceedings of SPIE, pp. 61-71, San Diego, Calif, USA, March 2004.

[11] R. C. Tennyson, A. A. Mufti, S. Rizkalla, G. Tadros, and B. Benmokrane, "Structural health monitoring of innovative bridges in Canada with fiber optic sensors," Smart Materials and Structures, vol. 10, no. 3, pp. 560-573, 2001.

[12] S. T. Kim, Y. Park, S. Y. Park, K. Cho, and J.-R. Cho, "A sensortype PC strand with an embedded FBG sensor for monitoring prestress forces," Sensors, vol. 15, no. 1, pp. 1060-1070, 2015.

[13] E. Li, J. Xi, J. F. Chicharo et al., “The experimental evaluation of FBG sensors for strain measurement of prestressed steel strand," in Smart Structures, Devices, and Systems II, vol. 5649 of Proceedings of SPIE, pp. 463-469, San Diego, Calif, USA, March 2005.

[14] Z. Zhou, Z. Zhang, N. Deng et al., "Applications of FRP-OFBG sensors on bridge cables," in Smart Structures and Materials 2005: Sensors and Smart Structures Technologies for Civil, Mechanical, and Aerospace Systems, vol. 5765 of Proceedings of SPIE, pp. 668-677, San Diego, Calif, USA, March 2005.

[15] Y.-S. Kim, H.-J. Sung, H.-W. Kim, and J.-M. Kim, "Monitoring of tension force and load transfer of ground anchor by using optical FBG sensors embedded tendon," Smart Structures and Systems, vol. 7, no. 4, pp. 303-317, 2011.

[16] J.-M. Kim, H.-W. Kim, Y.-H. Park, I.-H. Yang, and Y.-S. Kim, "FBG sensors encapsulated into 7-wire steel strand for tension monitoring of a prestressing tendon," Advances in Structural Engineering, vol. 15, no. 6, pp. 907-917, 2012.

[17] A. Othonos and K. Kalli, Fiber Bragg Gratings, Artech House, London, UK, 1999. 


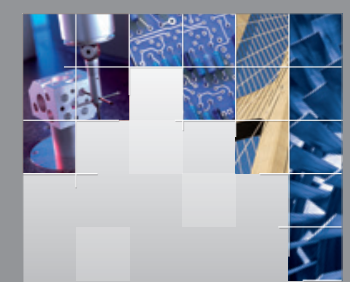

\section{Enfincering}
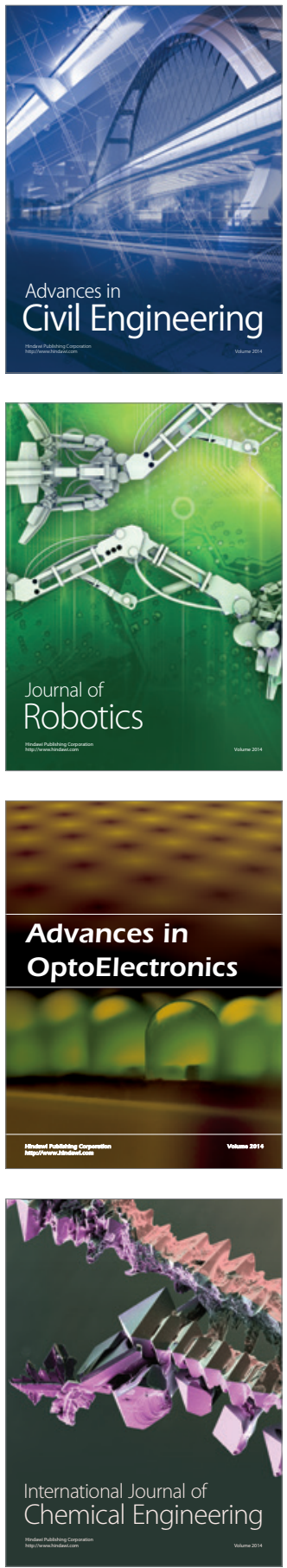

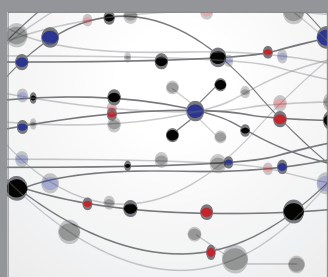

The Scientific World Journal

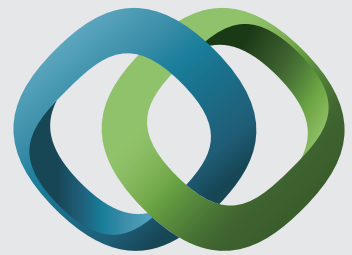

\section{Hindawi}

Submit your manuscripts at

http://www.hindawi.com
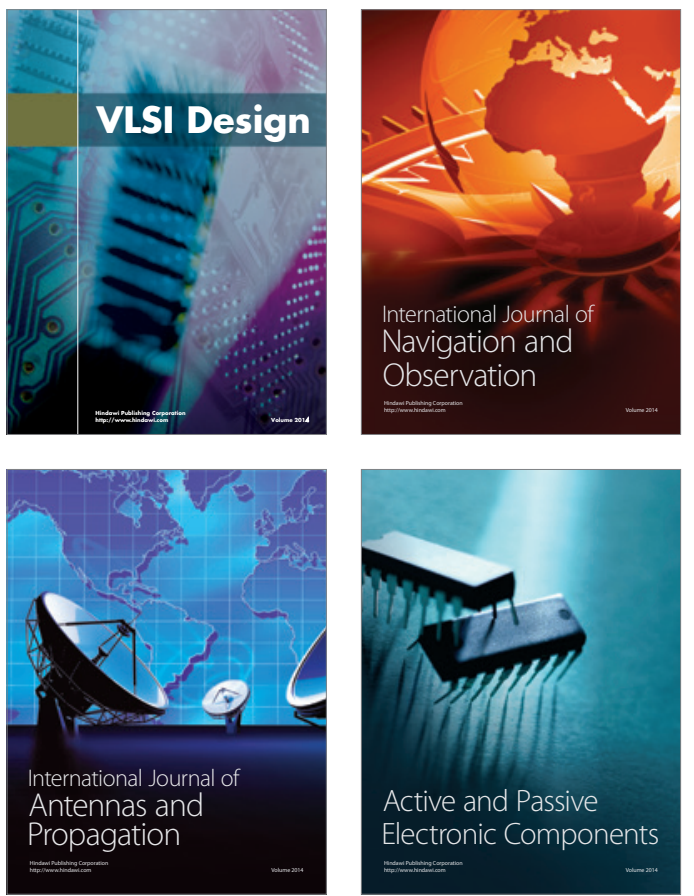
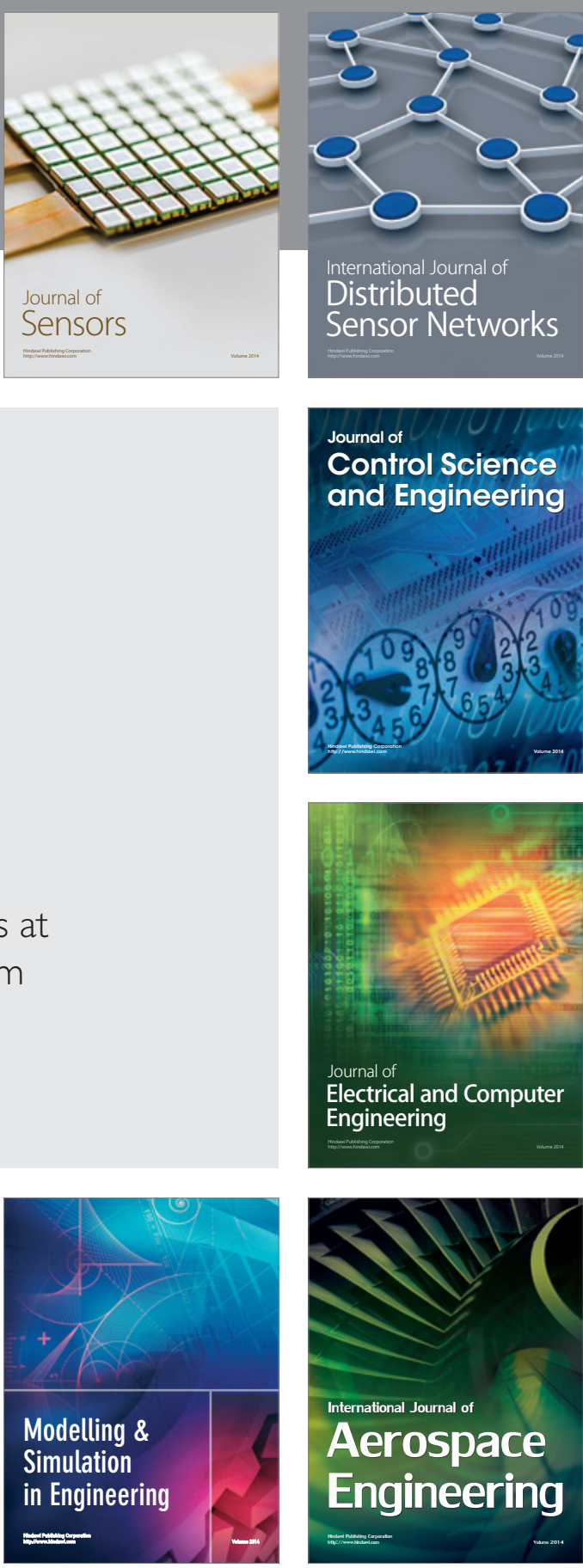

International Journal of

Distributed

Sensor Networks

Journal of

Control Science

and Engineering
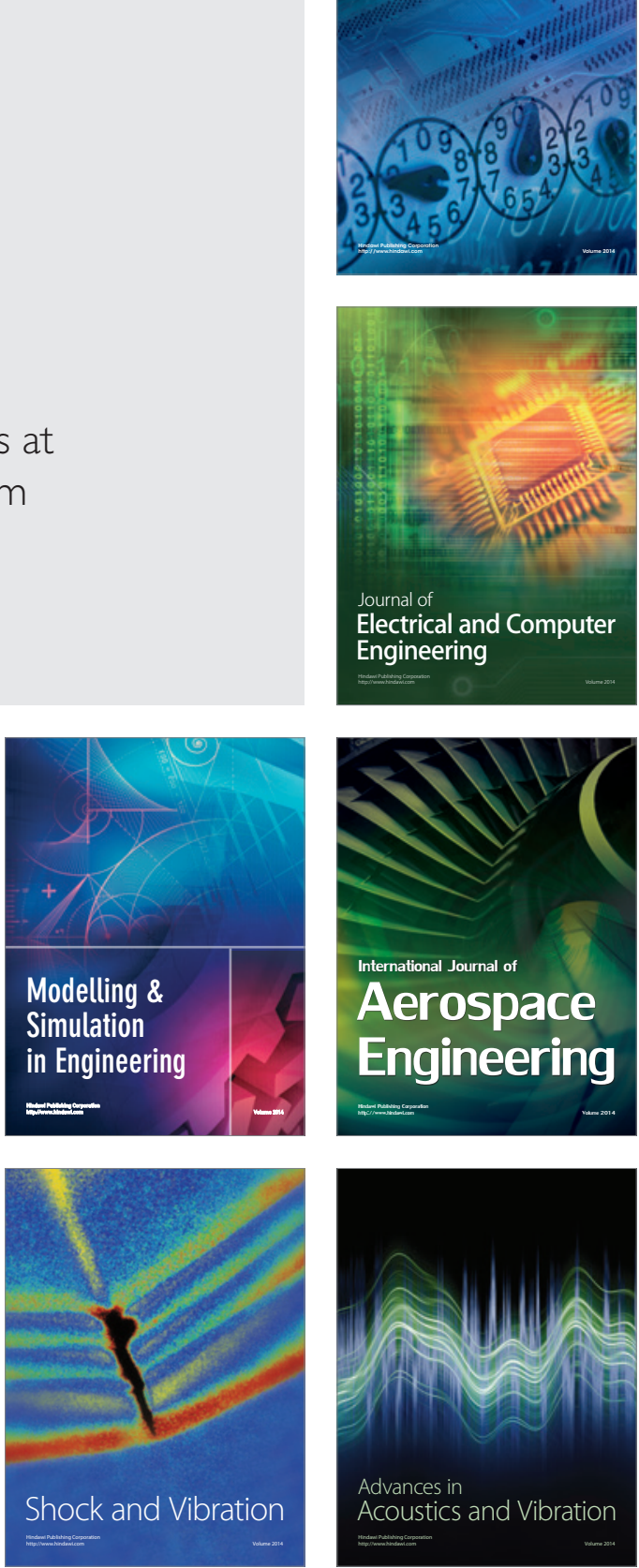